\title{
All these wishes will not be just wishes
}

\author{
Manh-Toan Ho \\ Centre for Interdisciplinary Social Research, Phenikaa University
}

Around four years after my first research project, and around 2 years since the pandemic swarming the world, I achieved an important milestone: 50 publications [1-52]. First, let me explain how I got to this point. At Centre for Interdisciplinary Social Research, we do not usually stick with one project but multiple ones. Moreover, our team is small, so each person has a distinct role in the team rather than a hierarchical dynamic. Lastly, while this might seem like a bad thing, but the publish-or-perish mentality can help with productivity [53]. I do not regret that I devoted a large portion of my past 4 years to research. It leads me to this point, to this achievement.

However, I do not know how to feel about this achievement, or should I even call it an achievement? I thought I would be proud, or at least happy. But now, I just have more questions than answers. Am I going too fast? I reached an absurd number of publications, but did I really contribute? Do my publications contribute anything significant? Eventually, during the timid lockdown in my country, I suddenly feel like I hate what I do, and I hate what I become.

I love football to death. People often equate football, and sports generally, with running a lot. However, a good footballer is someone who be at the right place at the right time, and he let the ball run for him, echoing Johan Cruyff and Pep Guardiola. So, the game becomes a bit like chess, where you outthink your opponent rather than outrun them. When I started to think about the game in this way, football becomes a good mental practice. However, there is another cold hard truth for players. You cannot win forever, and it always hit hard when you lose. So, the paradox is "Quality without results is pointless. Results without quality is boring," once again echoing Johan Cruyff.

Heading to the number 50, fast, feels like results without quality. Even though I still fight my way out with reviewers or face multiple rejections, there is still some underlying unsatisfactory.

Recently, I read two articles with an almost-identical title: "The natural selection of X science," with the X contains two opposing adjectives: good and bad. The good article [54] emphasized on the importance of theory development to the quality of science. The amount of time spending on developing good theories will often flourish in good research practices. Meanwhile, the bad article [55] emphasized on the evolution of research methods. In an environment where publications are the main criteria for career development, certain methods of analysis will often be used to maximize publications. In long term, the prioritization of quantity over quality will 
leads to poorer methods. Even though the two articles discussed different aspects of science, their messages are identical: good science takes time. Just like to play good football, you have to play at your own pace.

In retrospect, I expected the 50 milestone would allow me some kind of freedom to pursuit something different. Be fast to establish yourself, then you can have your own chance to work on your own things. Thus, as a young man fresh out of college, I rushed to work. I had time, health, and a little bit of ambition to try. Four years later, I just feel tired. I feel sleepy during the day, but staying too late during the night. I realize my body aching more often. Somehow, I had to change my glass for short-sightedness. For a 26-year-old boy, I thought they are small things, and sometime negligible.

"Man is condemned to be free; because once thrown into the world, he is responsible for everything he does."-Jean-Paul Satre [56].

So, the 50 milestone did not come easy. I do not like to say that I paid my price to be there, but it is true. There is always a price to pay. My mentor is proud of his three world view essays published in Nature's journals [53,57, 58]. They are not heavily technical or full of scientific jargon. They are short and concise. And now, they are deservedly my lighthouses. Why? Because they offered me a glimpse of what to come after the 50 milestone. Come to think about it, they are an accumulation of all my mentor's previous works. Precisely because my mentor had done many works before that he could finally bring the ideas to life, and in the manner that they are.

So, I wish that I will have more freedom to take care of myself. I wish that I will have more freedom to understand science and practice good science. I wish that I can work in long-term projects that will contribute meaningfully to my community. I wish that ... all these wishes will not be just wishes.

\section{References}

1. Ho, M. T., Ho, M. T., \& Vuong, Q. H. (2021). Total SciComm: A Strategy for Communicating Open Science. Publications, 9(3), 31, DOI: 10.3390/publications9030031.

2. Cao, Q. T., et al. (2021). A Bibliometric Review of Research on International Students' Mental Health: Science Mapping of the Literature from 1957 to 2020. European Journal of Investigation in Health, Psychology and Education, 11(3), 781-795, DOI: 10.3390/ejihpe11030056.

3. Vuong, Q. H, \& Ho, M. T. (2021). The need for economics education in Vietnam high school curriculum: A preliminary observation. Academia Letters, 1053, DOI: 10.20935/AL1053.

4. Vuong, Q. H., et al. (2021). An Al-Enabled Approach in Analyzing Media Data: An Example from Data on COVID-19 News Coverage in Vietnam. Data, 6(7), 70, DOI: 10.3390/data6070070.

5. Ho, M. T., et al. (2021). A Systematic and Critical Review on the Research Landscape of Finance in Vietnam from 2008 to 2020. Journal of Risk and Financial Management, 14(5), 219, DOI: $10.3390 / j r f m 14050219$. 
6. Vuong, Q. H., et al. (2021). Assessing the ideological homogeneity in entrepreneurial finance research by highly cited publications. Humanities and Social Sciences Communications, 8 , 110, DOI: 10.1057/s41599-021-00788-9.

7. Vuong, Q. H., et al. (2021). Adopting open access in an emerging country: Is gender inequality a barrier in humanities and social sciences?. Learned Publishing, DOI: 10.1002/leap.1387.

8. Nguyen, M. H., et al. (2021). Alice in Suicideland: Exploring the Suicidal Ideation Mechanism through the Sense of Connectedness and Help-Seeking Behaviors. International Journal of Environmental Research and Public Health, 18(7), 3681, DOI: 10.3390/ijerph18073681.

9. Vuong, Q. H., et al. (2021). A Data Collection on Secondary School Students' STEM Performance and Reading Practices in an Emerging Country. Data Intelligence, 3(2), 336-356, DOI: 10.1162/dint_a_00091.

10. Vuong, Q. H., et al. (2021). Top economics universities and research institutions in Vietnam: evidence from the SSHPA dataset. Heliyon, 7(2), e06273, DOI: 10.1016/j.heliyon.2021.e06273.

11. Vuong, Q. H., et al. (2021). On the environment-destructive probabilistic trends: a perceptual and behavioral study on video game players. Technology in Society, 101530, DOI: 10.1016/j.techsoc.2021.101530.

12. Vuong, Q. H., et al. (2020). Mirror, mirror on the wall: is economics the fairest of them all? An investigation into the social sciences and humanities in Vietnam. Research Evaluation, rvaa036, DOI: 10.1093/reseval/rvaa036.

13. Vuong, Q. H., et al. (2021). Identifying the moral-practical gaps in corporate social responsibility missions of Vietnamese firms: An event - based analysis of sustainability feasibility. Corporate Social Responsibility and Environmental Management, 28(1), 30-41, DOI: 10.1002/csr.2029.

14. Nguyen, M. H., et al. (2021). On the social and conceptual structure of the 50 -year research landscape in entrepreneurial finance. SN Business \& Economics, 1, 2, DOI: 10.1007/s43546-020-00002-z.

15. Vuong, Q. H., \& Ho, M. T. (2020). Rethinking editorial management and productivity in the COVID-19 pandemic. European Science Editing, 46, e56541, doi: 10.3897/ese.2020.e56541.

16. Ho, M. T., et al. (2020). An analytical view on STEM education and outcomes: Examples of the social gap and gender disparity in Vietnam. Children and Youth Services Review, 119, 105650, DOI: 10.1016/j.childyouth.2020.105650.

17. Vuong, T. T., et al. (2020). Adopting open access in the social sciences and humanities: evidence from a developing nation. Heliyon, 6(7), e04522, DOI: 10.1016/j.heliyon.2020.e04522.

18. Ho, M. T., et al. (2020). The internal capability of Vietnam social sciences and humanities: A perspective from the 2008-2019 dataset. Publications, 8(2), 32, DOI: 10.3390/publications8020032. 
19. Vuong, Q. H., et al. (2020). Bayesian analysis for social data: A step-by-step protocol and interpretation. MethodsX, 7, 100924, doi: 10.1016/j.mex.2020.100924.

20. Pham, T. H., et al. (2020). Entrepreneurial finance: Insights from English language training market in Vietnam. Journal of Risk Financial Management, 13(5), 96, DOI: 10.3390/jrfm13050096.

21. Tran, T., et al. (2020). How digital natives learn and thrive in the digital age: Evidence from an emerging economy. Sustainability, 12(9), 3819, DOI: 10.3390/su12093819.

22. Vuong, Q. H., et al. (2020). On how religions could accidentally incite lies and violence: Folktales as a cultural transmitter. Palgrave Communications, 6, 82, doi:10.1057/s41599020-0442-3.

23. Vuong, Q. H., et al. (2020). Improving Bayesian statistics understanding in the age of Big Data with the bayesvl $\mathrm{R}$ package. Software Impacts, 4, 100016, DOI: 10.1016/j.simpa.2020.100016.

24. Vuong, Q. H., et al. (2020). What have Vietnamese scholars learned from researching entrepreneurship? A Systematic review. Heliyon, 6(4), e03808, DOI: 10.1016/j.heliyon.2020.e03808.

25. Vuong, Q. H., et al. (2020). Multi-faceted insights of entrepreneurship facing a fast-growing economy: A literature review. Open Economies, 3(1), 25-41, DOI: 10.1515/openec-20200002.

26. La, V. P., et al. (2020). Policy response, social media and science journalism for the sustainability of the public health system amid the COVID-19 outbreak: The Vietnam lessons. Sustainability, 12(7), 2931, DOI: 10.3390/su12072931.

27. Nguyen, T. T. H., et al. (2020). How scientific research changes the Vietnamese higher education landscape: Evidence from social sciences and humanities between 2008 and 2019. F1000Research, 9, 152, DOI: 10.12688/f1000research.21790.1

28. Vuong, Q. H., et al. (2020). Making social sciences more scientific: Literature review by structured data. MethodsX, 100818. DOI: 10.1016/j.mex.2020.100818

29. Vuong, Q. H., et al. (2020). Characteristics of retracted articles based on retraction data from online sources through February 2019. Science Editing, 7(1), 34-44, DOI: $10.6087 /$ kcse. 187

30. Nguyen, M. H., et al. (2020). A scientometric study on depression among university students in East Asia: Research and system insufficiencies?. Sustainability, 12(4), 1498, DOI: 10.3390/su12041498.

31. Tran, T., et al. (2020). Scrambling for higher metrics in the Journal Impact Factor bubble period: a real-world problem in science management and its implications. Problems and Perspectives in Management, 18(1), 48-56, DOI: 10.21511/ppm.18(1).2020.05.

32. Le, T. T. H., et al. (2019). Reading habits, socioeconomic conditions, occupational aspiration and academic achievement in Vietnamese junior high school students. Sustainability, 11(1), 5113, DOI: 10.3390/su11185113. 
33. Vuong, Q. H., et al. (2019). Cultural evolution in Vietnam's early 20th century: a Bayesian networks analysis of Hanoi Franco-Chinese house designs. Social Sciences \& Humanities Open, DOI: 10.1016/j.ssaho.2019.100001.

34. Nguyen, M. H., et al. (2019). A dataset of students' mental health and help-seeking behaviors in a multicultural environment. Data, 4(3), 124, DOI: 10.3390/data4030124.

35. Tran, T., et al. (2019). The relationship between birth order, sex, home scholarly culture and youths' reading practices in promoting lifelong learning for sustainable development in Vietnam. Sustainability, 11(16), 4389, DOI: 10.3390/su11164389.

36. Le, A. V., et al. (2019). Exploration of youth's digital competencies: A dataset in the educational context of Vietnam. Data, 4(2), 69, DOI: 10.3390/data4020069.

37. Ho, M. T., et al. (2019). Health care, medical insurance, and economic destitution: A dataset of 1042 stories. Data, 4(2), 57, DOI: 10.3390/data4020057.

38. Vuong, Q. H., et al. (2019). A dataset of Vietnamese junior high school students' reading preferences and habits. Data, 4(2), 49, DOI: 10.3390/data4020049.

39. Tran, B. X., et al. (2019). Global evolution of research in Artificial Intelligence in health and medicine: A bibliometric study. Journal of Clinical Medicine, 8(3), 360, DOI: 10.3390/jcm8030360.

40. Vuong, Q. H., et al. (2019). Artificial intelligence vs. Natural stupidity: Evaluating Al readiness for the Vietnamese medical information system. Journal of Clinical Medicine, 8(2), 168, DOI: 10.3390/jcm8020168.

41. Vuong, Q. H., et al. (2019). Sex differences and psychological factors associated with general health examinations participation: Results from a Vietnamese cross-section dataset. Sustainability, 11(2), 514, DOI: 10.3390/su11020514.

42. Vuong, Q. H., et al. (2018). Cultural additivity: behavioural insights from the interaction of Confucianism, Buddhism and Taoism in folktales. Palgrave Communications, 4, 143, DOI: 10.1057/s41599-018-0189-2.

43. Vuong, Q. H., et al. (2018). "Paintings can be forged, but not feeling": Vietnamese artMarket, fraud, and value. Arts, 7(4), 62, DOI:10.3390/arts7040062.

44. Vuong, Q. H., et al. (2018). An open database of productivity in Vietnam's social sciences and humanities for public use. Scientific Data, 5, 180188, DOI:10.1038/sdata.2018.188.

45. Vuong, T. T., et al. (2018). The (in)significance of socio-demographic factors as possible determinants of Vietnamese social scientists' contribution-adjusted productivity: Preliminary results from 2008-2017 Scopus data. Societies, 8(1), 3 DOI: 10.3390/soc8010003.

46. Vuong, Q. H., et al. (2021). Bản hòa tấu dũ liệu xã hội. Nxb Khoa học Xã hội, Hà Nội.

47. Nguyen, T. T., et al. (2019). Chapter 2. Scientific publishing: a slow but steady rise. In QuanHoang Vuong, Trung Tran (Eds.), The Vietnamese Social Sciences at a Fork in the Road (pp. 33-51). Warsaw, Poland: De Gruyter. https://doi.org/10.2478/9783110686081-007

48. Nguyen, T. H. K., et al. (2019). Chapter 7. Scientific publishing: the point of no return. In QuanHoang Vuong, Trung Tran (Eds.), The Vietnamese Social Sciences at a Fork in the Road (pp. 143-162). Warsaw, Poland: De Gruyter. https://doi.org/10.2478/9783110686081-012 
49. Ho, M. T., et al. (2019). Chapter 8. The emerging business of science in Vietnam. In QuanHoang Vuong, Trung Tran (Eds.), The Vietnamese Social Sciences at a Fork in the Road (pp. 163-177). Warsaw, Poland: De Gruyter. https://doi.org/10.2478/9783110686081-013

50. Vuong, Q. H., et al. (2018). To be human in the age of Industry 4.0: Perspective from Vietnam. Proceedings of the XXIV World Congress of Philosophy 2018 (Beijing).

51. Vuong, Q. H., et al. (2020). Earth Hour in Vietnam: a perspective from the electricity industry. Behavioural and Social Sciences at Nature Research. URL: https://socialsciences.nature.com/users/301097-ho-manh-toan/posts/66561-earthhour-in-vietnam-a-perspective-from-the-electricity-industry

52. Ho, M. T., et al. (2019). To walk on the Penrose stairs of science. Behavioural and Social Sciences at Nature Research. URL: https://socialsciences.nature.com/channels/2140-is-itpublish-or-perish/posts/54541-to-walk-on-the-penrose-stairs-of-science.

53. Vuong, Q. H. (2019). Breaking barriers in publishing demands a proactive attitude. Nature Human Behaviour, 3(10), 1034.

54. Stewart, A. J., \& Plotkin, J. B. (2021). The natural selection of good science. Nature Human Behaviour, 1-9.

55. Smaldino, P. E., \& McElreath, R. (2016). The natural selection of bad science. Royal Society Open Science, 3(9), 160384.

56. Sartre, J. P. (1943). Being and Nothingness. Washington Square Press [1993 Reprint Version]

57. Vuong, Q. H. (2018). The (ir)rational consideration of the cost of science in transition economies. Nature Human Behaviour, 2(1), 5.

58. Vuong, Q. H. (2020). Reform retractions to make them more transparent. Nature, 582(7811), 149. 